\title{
Adaptive robust control design to enhance smart grid power system stabilization using wind characteristics in Indonesia
}

\author{
Khamda Herbandono, Cuk Supriyadi Ali Nandar \\ Agency for The Assesment and Application of Technology, Puspiptek Office. South Tangerang, Banten, Indonesia
}

\begin{tabular}{l} 
Article Info \\
\hline Article history: \\
Received Jun 15, 2021 \\
Revised Aug 13, 2021 \\
Accepted Aug 20, 2021 \\
\hline
\end{tabular}

\section{Keywords:}

Adaptive control

PI controller

Power system stabilization

Robust control design

Smart grid

Wind power

\begin{abstract}
This paper is interested to study power system stability in smart grid power system using wind characteristic in south of Yogyakarta, Indonesia. To overcome the intermittent of wind characteristics, this paper presents adaptive robust control design to enhance power system stabilization. The online identification system is used in this research, which updated whenever the estimated model mismatch exceeds predetermined bounds. Then genetic algorithm (GA) is applied to re-tune parameters controller based on the estimated model. The structure of controller is proportional integral (PI) controller due to the most applicable in industry, simple structure, low cost and high reliability. Robustness of controller is guaranteed by taking system uncertainties into consideration. The performance of the proposed controller has been carried out in a hybrid wind-diesel power system in comparison with previous work controller. Simulation results confirm that damping effect of the proposed controllers are much better that of the conventional controllers against various operating.
\end{abstract}

This is an open access article under the CC BY-SA license.

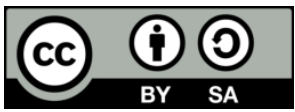

\section{Corresponding Author:}

Cuk Supriyadi Ali Nandar

Agency for The Assessment and Application of Technology

Technology Building 251 2nd Floor, Puspiptek Office. South Tangerang, Banten, Indonesia

Email: cuk.supriyadi@bppt.go.id

\section{INTRODUCTION}

Recently, renewable energy sources become a more attractive choice for electricity. One of the most familiar renewable energy is wind energy. Wind power as one of renewable energy sources is expected to be economically attractive when the wind speed in the proposed site is considerable for electrical generation and electric energy in that site is not easily available from the grid [1]. However, the intermittence and fluctuation of output power of wind power generation may cause a serious problem of frequency fluctuation of the isolated micro grid [2]. To get high quality power system, the smart grid technologies applications such as distributed energy storage and smart controller devices for mitigating impacts of the integration of renewable energy generation are highly needed [3].

Several control methods for frequency stabilization by applying pitch angle of wind power generation have been reported [4]-[6]. In these works, however, they only focus on the design of pitch controller in the wind site without considering governor controller in the diesel side. To improve the frequency stability in isolated power system, some previous research works have successfully proposed control design methods of the pitch controller in the wind side and the governor in the diesel side simultaneously. To damp the frequency fluctuation, optimization of controller parameters using ISE technique [7] and fuzzy logic [8] have been proposed. In [9], [10], the authors proposed load frequency control method with combining a PID controller and a disturbance observer for large penetration of wind power generations. This work can significantly improve the performance of the controllers and power 
system. Nevertheless, under the sudden change of load demands and random wind power input, the pitch controller of the wind side and the governor of the diesel side may no longer be able to effectively control the system frequency due to their slow response.

Energy storages such as fuel cell, flywheel, battery, superconducting magnetic energy storage (SMES), which are able to supply and absorb active power rapidly [11], [12], have been highly expected as the most effective controllers of system frequency. Superconducting magnetic energy storage has been successfully applied to solve many problems in power systems such as an improvement of power system dynamics [13], [14], a load leveling [15], a frequency control in hybrid wind-diesel power systems [16]-[18]. However, SMES is very costly in comparison with the common energy storage such as battery.

In [19], [20], design of robust battery controller in a hybrid wind-diesel power system by Ho control has been proposed. In this work, the controller has presented high robustness controller against various uncertainties. However, the order of $\mathrm{H} \infty$ controller depends on that of the plant and the weighting functions of the controller cannot be selected easily. This leads to the complex structure controller in comparison with conventional PI or lead/lag compensator, and also the pitch and battery controller in this work have been designed separately while the control parameters of governor are fixed. This method may not be able to guarantee the well coordinated control between governor, pitch and battery controller. To enhance the coordinated control, the simultaneous optimization of robust governor, pitch and battery controller is highly expected.

This paper proposes adaptive PI pitch and battery controller using a system estimator. The system estimator is developed by minimizing mismatch error between output signal of the real system and estimated model using GA. To guarantee performance of the controller, the improvement of damping ratio is applied to formulate an optimization problem. GA is employed to achieve optimum or near optimum for the controller parameters. As a result, without the availability of all system parameters and exact models, the steady state sampling data of power system can be used to construct the system estimator and tune parameters of controllers

This paper proposes technique that gives adaptivity as well as robustness to the conventional type of controllers. In the adaptive proposed controller, the parameters of controller are changed depending on the condition of system operation to avoid the parameters changes too frequently so that the parameter alteration is done at the right moment. This demands for a method that can detect when to change the parameters and a method that determines how they should be changed. The identified model is used to monitor discrepancy between the actual power system output and the expected output (model output). When a large discrepancy is detected, a new set of controller parameters is determined to adapt to the new situation. The effectiveness of proposed method is evaluated in hybrid wind-diesel power system in comparison with the conventional controller.

\section{SYSTEM MODELING}

\subsection{Hybrid wind-diesel power system}

In Figure 1 depicts the basic system configuration of an isolated hybrid wind-diesel power system which will be used to design the coordinated robust frequency controller of governor, pitch and battery controllers. This system consists of a diesel generator, a wind power generation and the load with base capacity is $300 \mathrm{~kW}$ [7]. The rated capacities of wind power generation and diesel are $150 \mathrm{~kW}$ and $150 \mathrm{~kW}$, respectively. The wind power generation produces an active power fluctuation, and the diesel is used as a back up to supply power to system when wind power could not adequately provide power to customer.

To solve this problem, the system needs to maintaining the balance of real power between supply and demand in the system. In this study, the real power deviation is suppressed by the diesel generator, the wind power generation, and the battery. Governor and pitch controller are equipped in the diesel side and the wind side, respectively, to help balance the distribution of real power in the system. However, the ability of the governor and pitch controllers to provide frequency control is not adequate due to their slow response. Accordingly, the battery energy storage is installed in the system to fast compensate for surplus or insufficient power demands, and minimize frequency deviation.

\subsection{Pitch and battery controller model}

The battery block diagram is depicted in Figure 2. The battery diagram is represented with two transfer functions, i.e., the PI based frequency controller and the battery model and. Based on [18], the battery can be modeled by the first-order transfer function with time constant $\mathrm{T}_{\mathrm{BATT}}=0.3 \mathrm{sec}$. In this work, the battery controller is presented by practically a 1st order PI controller with single feedback input signal, system frequency deviation $(\Delta \mathrm{fS})$. The rated capacity of inverter is $15 \mathrm{~kW}(0.05 \mathrm{pu})$, and the rated capacity of battery is $30 \mathrm{kWh}$. Note that the system in (1) is a multi-input multi-output (MIMO) system. 


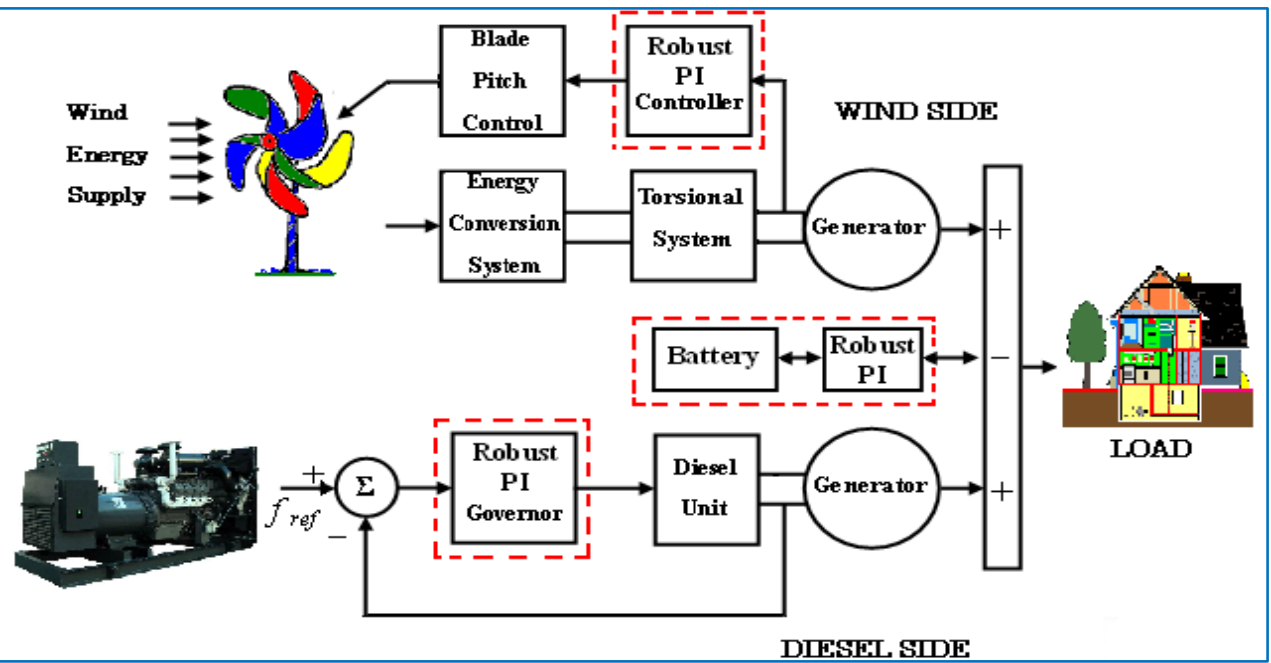

Figure 1. Basic configuration of an isolated power system with pitch and battery controllers

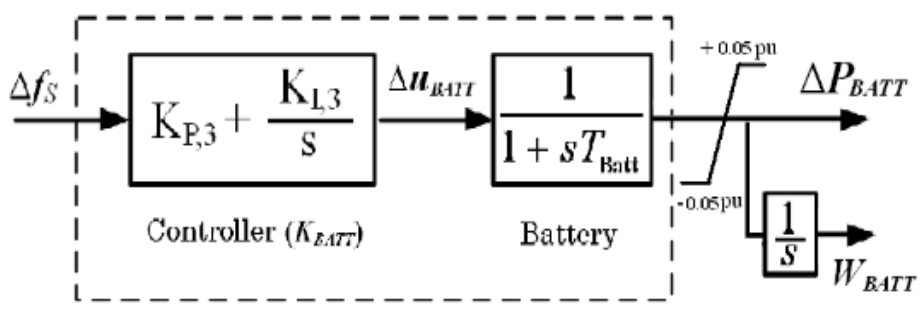

Figure 2. Block diagram of battery with the controller

\section{PROPOSED ADAPTIVE ROBUST CONTROLLER}

Diagram of the proposed adaptive robust control design is shown in Figure 3. In the proposed adaptive control, a system identification technique and the robust controller design method are combined into an indirect adaptive controller design [21], [22]. The identified model is used to monitor discrepancy between the actual power system output and the expected output (model output). The new set of controller parameters is determined to adapt to the new situation when a large discrepancy is detected. The robust control design is applied to guarantee robustness of controller. The several given identified models and corresponding controller parameters will be stored in memory, so that we have model and controller banks. The model and controller bank have an advantage, the system re-uses them in the similar situations without model identification and controller parameters re-tuning.

The goal of system identification is to characterize the dynamic input-output relation of the underlying process [22]-[24]. In this study, output error (OE) identification method is used to construct the estimated model of each generator because the OE model is easily computed, familiarly used and has high accuracy. To consider the robust control, the inverse additive perturbation is applied in this study [25], [26]. By minimizing $\|G(s) /(1+G(s) K(s))\|_{\infty}$, the robust stability value of the closed-loop system is near optimum.

Each step of the proposed method for model identification, and adaptive robust controller design is explained as shown in:

- $\quad$ Step 1. Comparison of the real system and the estimated model:

In this step, the output signal of both the real and the estimated system are compared as 'mismatch error' and the estimated model will be updated whenever the mismatch exceeds predetermined bound $(\Delta \varepsilon)$. When the operating condition of the real system move to a new condition and the mismatch exceeds the predetermined bound, the system will look at memory to check the availability of the matching estimated model. If the memory has the matching estimated model, then the system will re-use it directly without model identification and controller parameters tuning. Otherwise, the system will develop a new estimated model and tune controller parameter. 
- $\quad$ Step 2. Develop a new estimated model:

A new estimated model is developed using output error (OE) system identification so that the mismatch error be less than or same as specification.

- $\quad$ Step 3. Parameters tuning of PI controller

Parameters of the 'virtual controller' based on the new estimated model will be tuned by increasing the damping ratio of the dominant mode of the power system and considering system uncertainties. The structure of controller is shown in (4)-(6):

$$
\text { PI controller: } K_{P I}=K_{P}+\frac{K_{I}}{s} \text {, }
$$

Where:

$K_{P}$ is a controller gain of PI controller.

$K_{I}$ is an integral parameter of PI controller.

The following optimization problem is applied to tune controller parameters,

$$
\text { Minimize }\|G /(1+G K)\|_{\infty}
$$

Subject to $\zeta \geq \zeta_{\text {spec }}, \sigma \leq \sigma_{\text {spec }}$

This optimization problem is solved by meta-heuristic method (genetic algorithm) [27]

- Step 4. Store the new controller parameters and the new estimated model and in the memory.

After the new controller parameter is successfully to improve the robustness and performance of the system, the new controller parameters and the new estimated model and will be stored in the memory to be used in the similar operating condition in the future without model identification and controller parameters tuning.

- $\quad$ Step 5. Apply the new controller parameters to the real controller in the actual system, and return to step 1.

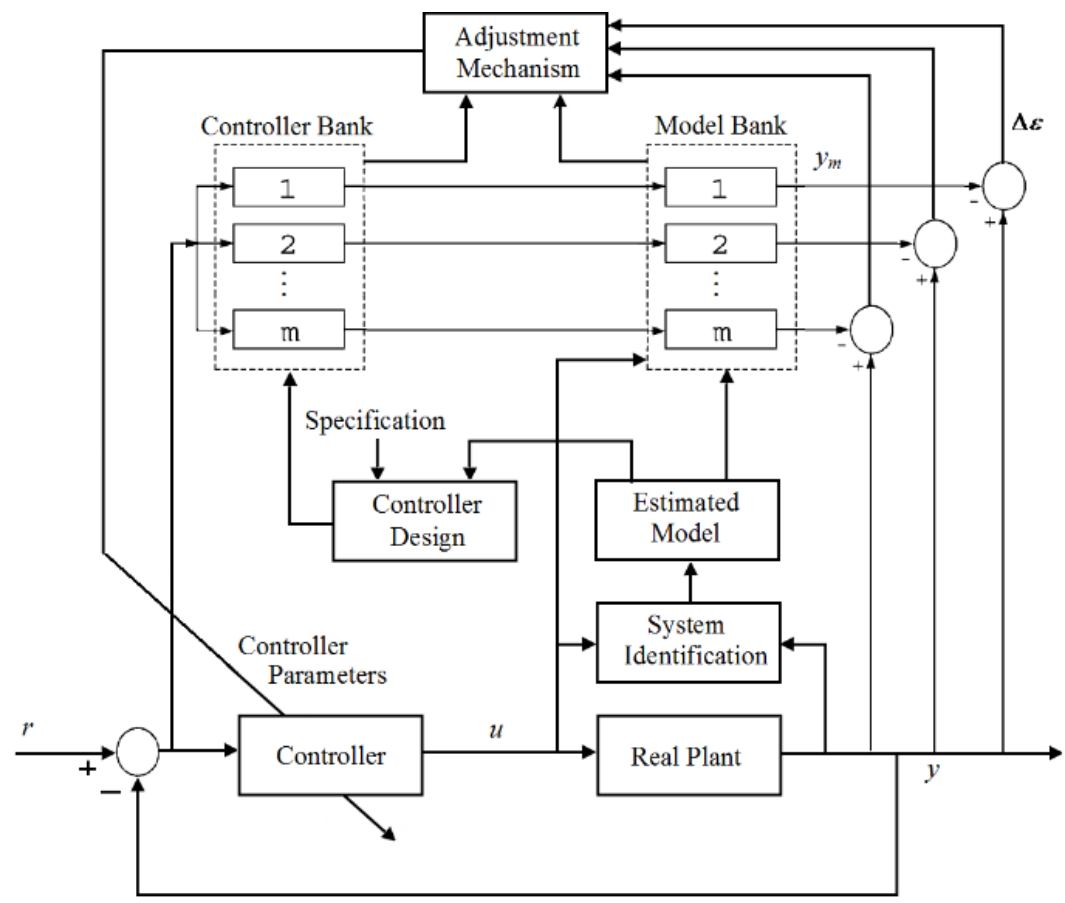

Figure 3. Architecture diagram of proposed indirect adaptive control

\section{SIMULATION RESULTS}

\subsection{Wind characteristic in Yogyakarta, Indonesia}

Figure 4 shows sample of wind speed in Yogyakarta for a week from Monday to Thursday. The wind speeds are measured at $50 \mathrm{~m}$ above the ground. Wind data shows that Indonesia especially Yogyakarta 
has wind speed average between 4-6 m/s, really in contrast to ranging Europe state within 9-12 m/s. However, the wind fluctuation at Yogyakarta is very extreme. To overcome the intermittent of wind characteristics, this paper presents adaptive robust control design to enhance smart grid power system stabilization.

\subsection{Develop estimated model}

First, identification system should be applied to construct estimated model. In this study, the estimated model is represented by a transfer function of $5^{\text {th }}$ order identical to the order of the isolated power system model. The period of data set which be used in the identification system is $60 \mathrm{~s}$. The different set of data is used to validate the estimated model. The simulation results of angular velocity deviation using validation data is shown in Figure 5. The simulation result confirms that the error between the measured output of the real system and the estimated model are smaller than specification, where the estimated model fit is $93.14 \%$. The results show that the estimated model has a similar characteristic with the real system.
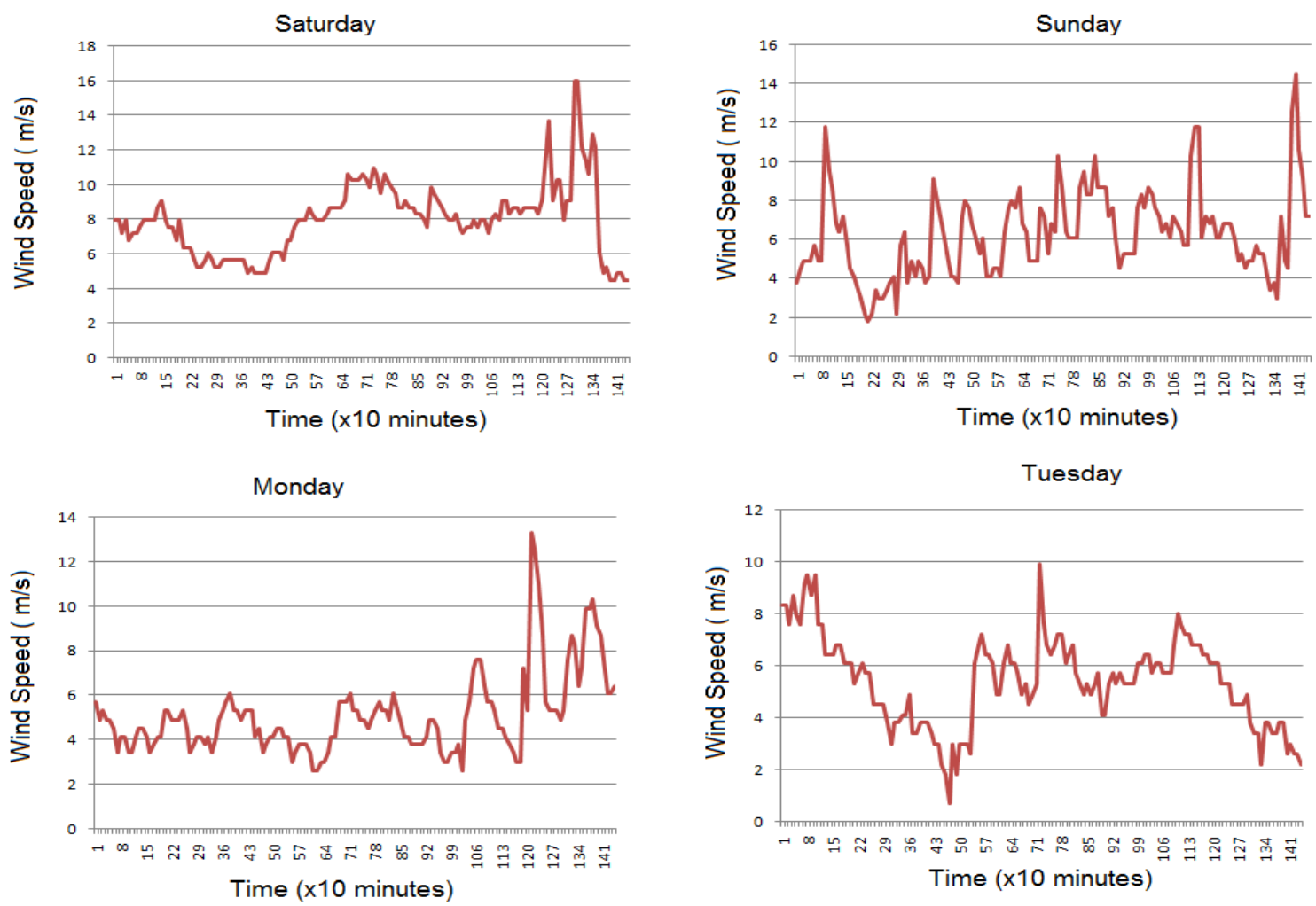

Wednesday

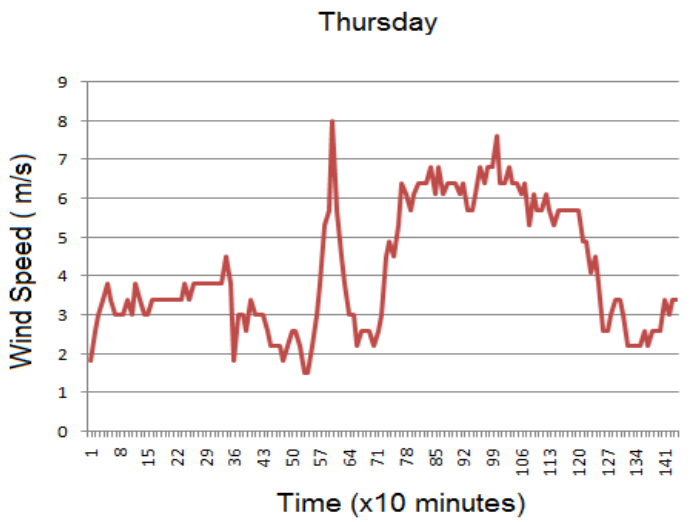

Figure 4. Wind characteristics at Yogyakarta, Indonesia 


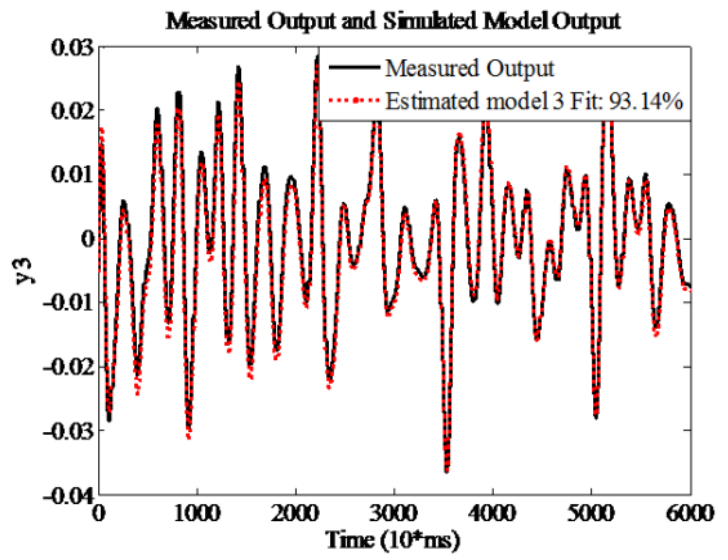

Figure 5. Validation of estimated model

\subsection{Controller parameter tuning}

Based on the new estimated model, PI controller parameters are tuned using the proposed robust control design. In the optimization, the ranges of search parameters are set as shown in: $\zeta_{\text {spec }}$, desired damping ratio, is set as $0.3, \sigma_{s p e c}$, desired real part, is set as $-0.3 . K_{P, i, m i n}$ and $K_{P, i, \max }$, minimum and maximum gains of pitch and battery controller, are set as 1 and $300, K_{I, i, \min }$ and $K_{I, i, \max }$, minimum and maximum integral parameter of pitch and battery controller, are set as 0.01 and 40. Moreover, the GA parameters are set as shown in: crossover probability is 0.9 , mutation probability is 0.05 , population size is 100 and maximum generation is 100. In simulation studies, the performance and robustness of the proposed PI controllers are compared with those of PI-controller [7].

\subsection{Apply the new controller parameters to the actual controller}

The effectiveness, performance, and robustness of the proposed controllers are examined by simulation studies under three operating conditions as shown as shown in:

- $\quad$ Case 1: Step input of wind power

In case 1 , step increase of $0.01 \mathrm{pu}$ on the system base of $300 \mathrm{~kW}$ in the wind power input and load change are applied to the system at $t=5.0 \mathrm{~s}$. Figure 6 shows the system frequency deviation. In system with PI controller [7], the peak frequency deviation is very large and takes longer time to reach steadystate. The results show that the pitch controller and the governor in the previous work do not work well. On the other hand, in case of the C-PI controller and the proposed PI controller are able to reduce frequency deviation significantly.

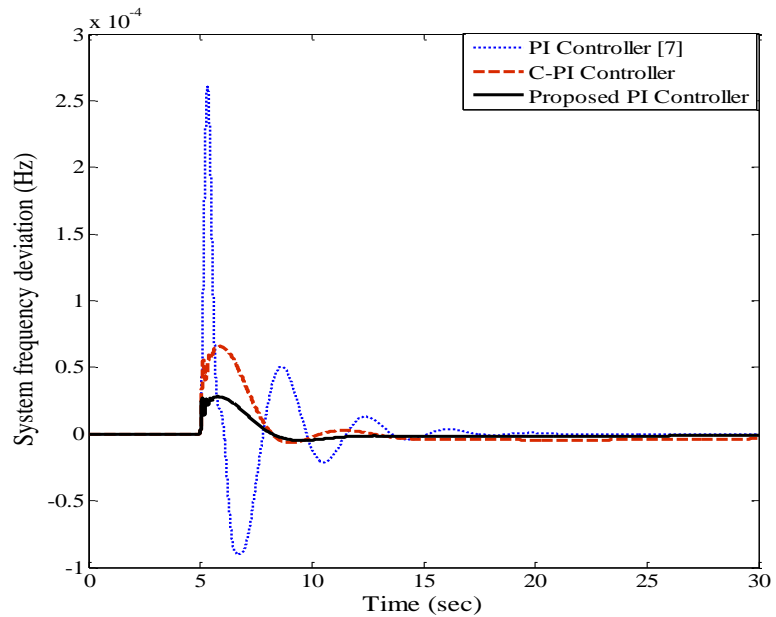

Figure 6. System frequency deviation against a step change of wind power 
- Case 2: Extreme operating condition.

The system is assumed change suddenly by changing the fluid coupling (Kfc) till $50 \%$ of the normal values. $\mathrm{Kfc}$ is chosen because $\mathrm{Kfc}$ is the most sensitive parameter in the system. It means that the control response of the power system very sensitive to Kfc changes. Figure 7 shows the response of frequency when $\mathrm{Kfc}$ is decreased, it may cause the error $(\Delta \varepsilon)$ is increasing until $36 \%$.

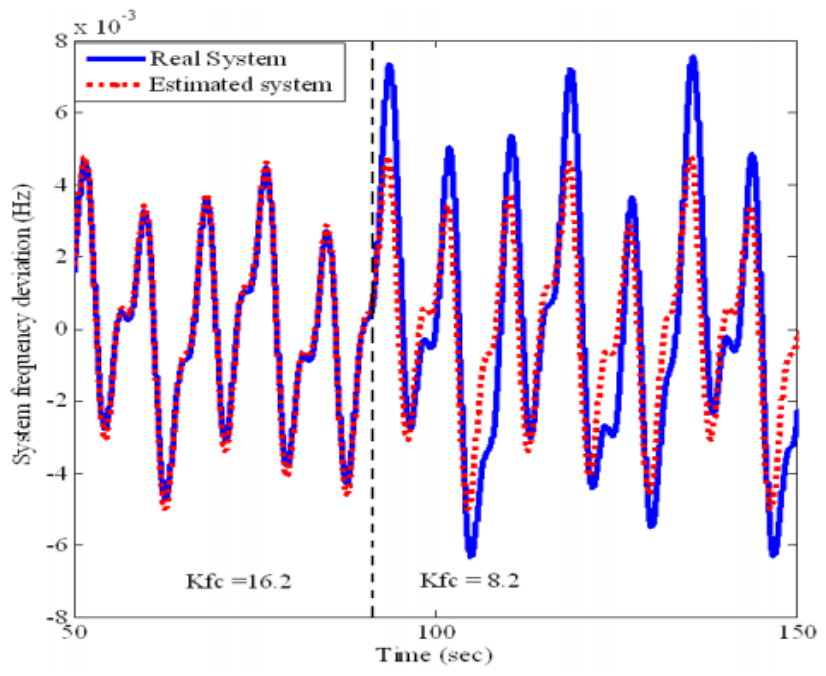

Figure 7. System response when Kfc is decreased by $50 \%$

To reduce $\Delta \varepsilon$, the proposed identification system method is applied to search new estimated model. As a result, the new estimated model achieved percent error $(\Delta \varepsilon)$ model for $60 \mathrm{Sec}$ simulations is decreased until around $1.85 \%$ as shown in Figure 8. Based on the new estimated model, pitch and battery parameters are tuned using the objective function as mentioned in (5). Then the new controller parameters are applied to the estimated model to check the response of the given controller parameters. The system response of frequency is shown in Figure 9. The overshoot of frequency fluctuation in cases of the new controller parameters is much lower than that of controllers before tuning. After that, the new parameters of controllers will be transferred to the real system. The simulation result after real system uses the new controller parameters depicts that the response of system frequency deviation is improved significantly. These results show that the proposed method of adaptive control using the online system estimator can be applied successfully for hybrid wind-diesel power system against various conditions.

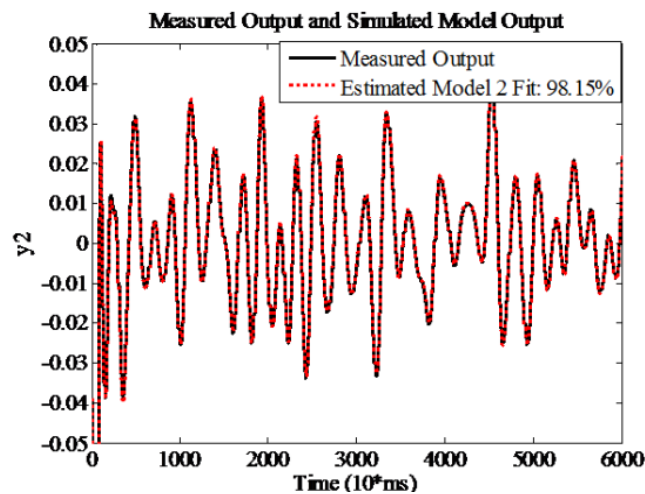

Figure 8. Validation of estimated model at extreme condition

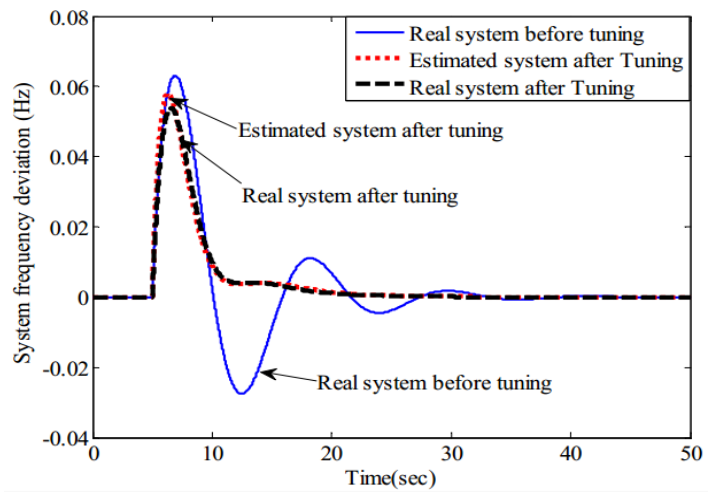

Figure 9. System response after control tuning 


\section{CONCLUSION}

The adaptive robust control to enhance frequency stability in isolated hybrid wind-diesel power system has been proposed in this work. Without the availability of all system parameters and exact models, steady state data obtained from power system can be used to construct estimated model by employing EO identification system. The estimated model can be used to tune PI parameters. To take system uncertainties into consideration in the PI parameters optimization, the inverse additive perturbation has been applied to represent unstructured system uncertainties. To improve the system robust stability against system uncertainties, the PI controller parameters have been automatically optimized by GA. A number of simulation tests in the hybrid wind-diesel power system confirm that the proposed control design is effective to stabilize the system against various conditions in comparison with the conventional controller without considering adaptivity.

\section{ACKNOWLEDGEMENTS}

This research was funded by a grant from the Indonesia Endowment Fund for Education (LPDP) Ministry of Finance Indonesia, grant No. PRJ-30/LPDP/2020.

\section{REFERENCES}

[1] T. Ackermann, "Wind power in power systems," 2nd Edition, John Wiley \& Sons Ltd, 2005.

[2] M. E. Gouveia and A. M. Matos, "Evaluating operational risk in a power system with a large amount of wind power," Journal of Electric Power Systems Research, vol. 79, pp. 734-739, 2009, doi: 10.1016/j.epsr.2008.10.006.

[3] A. Arulampalam, M. Barnes, N. Jenkins, J. Ekanayake, "Power quality and stability improvement of a wind farm using STATCOM supported with hybrid battery energy storage," IET Proceedings - Generation Transmission and Distribution, vol. 153, pp. 701-710, 2006, doi: 10.1049/ip-gtd:20045269.

[4] T. Senjyu, R. Sakamoto, N. Urasaki, T. Funabashi, H. Fujita and H. Sekine, "Output power leveling of wind turbine Generator for all operating regions by pitch angle control," in IEEE Transactions on Energy Conversion, vol. 21, no. 2, pp. 467-475, June 2006, doi: 10.1109/TEC.2006.874253.

[5] T. S. Bhatti, A. A. F. Al-Ademi, and N. Bansal, "Dynamics and control of isolated wind-diesel power systems," International Journal of Energy Research, vol. 19, pp. 729-740, 1995, doi: 10.1002/ER.4440190810.

[6] E. Muljadi and C. P. Butterfield, "Pitch-controlled variable-speed wind turbine generation," in IEEE Transactions on Industry Applications, vol. 37, no. 1, pp. 240-246, Jan.-Feb. 2001, doi: 10.1109/28.903156.

[7] S. C. Tripathy, M. Kalantar, and N. D. Rao, "Dynamic and stability of a wind stand-alone power system," Energy Conversion and Management, vol. 34, pp.627-640, 1993, doi: 10.1016/0196-8904(93)90097-T.

[8] S. Shibasaki, H. Onishi and S. Iwamoto, "A study on load frequency control combining a PID controller and a disturbance observer," 2009 Transmission \& Distribution Conference \& Exposition: Asia and Pacific, 2009, pp. 14, doi: 10.1109/TD-ASIA.2009.5356861.

[9] K. Abe, S. Ohba and S. Iwamoto, "New load frequency control method suitable for large penetration of wind power generations," 2006 IEEE Power Engineering Society General Meeting, 2006, pp. 6 pp.-, doi: 10.1109/PES.2006.1709177.

[10] C. Chokpanyasuwan, "Robust Fuzzy logic-PID Controller for Wind-Diesel Power System using Particle Swarm Optimization," GMSARN International Conference on Sustainable Development: Issues and Prospects for the GMS, 2008.

[11] D. Sutanto and K. W. E. Cheng, "Superconducting magnetic energy storage systems for power system applications," 2009 International Conference on Applied Superconductivity and Electromagnetic Devices, 2009, pp. 377-380, doi: 10.1109/ASEMD.2009.5306614.

[12] H. J. Boenig and J. F. Hauer, "Commissioning Tests of The Bonneville Power Administration 30 MJ Superconducting Magnetic Energy Storage Unit," in IEEE Transactions on Power Apparatus and Systems, vol. PAS-104, no. 2, pp. 302-312, Feb. 1985, doi: 10.1109/TPAS.1985.319044.

[13] Y. Mitani, K. Tsuji and Y. Murakami, "Application of superconducting magnet energy storage to improve power system dynamic performance," in IEEE Transactions on Power Systems, vol. 3, no. 4, pp. 1418-1425, Nov. 1988, doi: $10.1109 / 59.192948$.

[14] J. B. X. Devotta and M .G. Rabbani, "Application of superconducting magnetic energy storage unit in multimachine power systems," Energy Conversion and Management, vol. 41, pp. 493-504, 2000, doi: 10.1016/S01968904(99)00100-4.

[15] M. Abdelsalam, R. Boom, H. Peterson, D. Helfrecht and W. Bratley, "Operational aspects of superconductive magnetic energy storage (SMES)," in IEEE Transactions on Magnetics, vol. 23, no. 5, pp. 3275-3277, September 1987, doi: 10.1109/TMAG.1987.1065483.

[16] S. C. Tripathy, "Dynamic simulation of hybrid wind-diesel power generation system with superconducting magnetic energy storage," Energy Conversion and Management, vol. 38, pp. 919-930, 1997, doi: 10.1016/S01968904(96)00093-3.

[17] L. Xiangjun, Y.-J. Song, and S.-B. Han, "Frequency control in micro-grid power system combined with electrolyzer system and fuzzy PI Controller," Journal of Power Sources, vol. 180, pp. 468-475, 2008, doi: 10.1016/j.jpowsour.2008.01.092. 
[18] T. Senjyu, A. Uehara, A. Yona and T. Funabashi, "Frequency control by coordination control of wind turbine generator and battery using Ho control," 2009 Transmission \& Distribution Conference \& Exposition: Asia and Pacific, 2009, pp. 1-4, doi: 10.1109/TD-ASIA.2009.5356848.

[19] A. N. Cuk Supriyadi, I. Ngamroo, S. Kaitwanidvilai, A. Kunakorn, T. Hashiguchi and T. Goda, "Robust Pitch Controller Design in Hybrid Wind-Diesel Power Generation System," 2008 3rd IEEE Conference on Industrial Electronics and Applications, 2008, pp. 1054-1059, doi: 10.1109/ICIEA.2008.4582678.

[20] A. N Cuk Supriyadi, "Parameter Optimization of Pitch Controller for Robust Frequency Control in an Isolated Wind-diesel Hybrid Power System Using Genetic Algorithm, "TELKOMNIKA, vol. 6, 3, p. 145, 2008, doi: 10.12928/telkomnika.v6i3.562.

[21] A. N. Cuk Supriyadi, H. Takano, J. Murata, T. Goda and T. Hashiguchi, "Adaptive Frequency Control for Hybrid Wind-Diesel power system using system estimator," 2012 IEEE International Conference on Power System Technology (POWERCON), 2012, pp. 1-6, doi: 10.1109/PowerCon.2012.6401449.

[22] A. N. Cuk Supriyadi, H Takano, J Murata, and T Goda, "Adaptive robust PSS to enhance stabilization of interconnected power systems with high renewable energy penetration, "Journal of Renewable energy, vol. 63, pp. 767-774, 2014, doi: 10.1016/j.renene.2013.09.044.

[23] T. Elie, T. Poinot, R. Ouvrard, and A. Abche, "Initialization of Output Error Identification Algorithms," PhD Thesis, The university of Balamand, Lebanon, 2008.

[24] G. P. Rao and H. Unbehauen, "Identification of continous-time systems," IFAC Proceedings Volumes, vol. 153, pp. 185-220, 2006, doi: 10.1016/S1474-6670(17)42970-3.

[25] P. Gu, Hr. Petkov, and M. M. Konstantinov, "Robust control design with MATLAB," Springer, London, 2005.

[26] A. N. Cuk Supriyadi et al., "Inverse additive perturbation-based optimization of robust PSS in an interconnected power system with wind farms," 2008 SICE Annual Conference, 2008, pp. 237-240, doi: 10.1109/SICE.2008.4654658.

[27] Y. L. Abdel-Magid, M. A. Abido, S. Al-Baiyat and A. H. Mantawy, "Simultaneous stabilization of multimachine power systems via genetic algorithms," in IEEE Transactions on Power Systems, vol. 14, no. 4, pp. 1428-1439, Nov. 1999, doi: 10.1109/59.801907.

\section{BIOGRAPHIES OF AUTHORS}

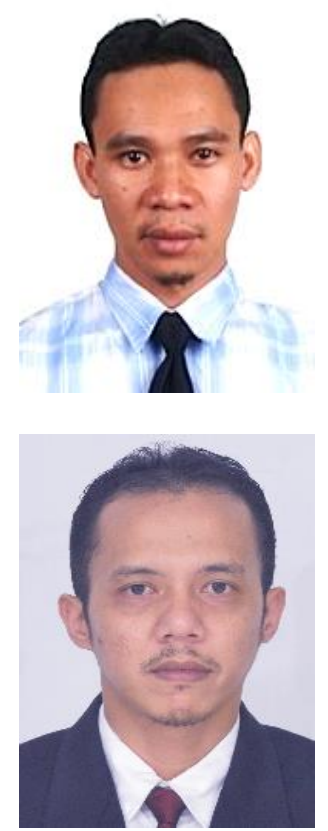

Cuk Supriyadi Ali Nandar was born in Blora, Indonesia, on January 15, 1980. He received B.Eng degree from Electrical Engineering Department, Gadjah Mada University in 2002. He earned his M.Eng Degree in Electrical Engineering of King Mongkut's Institute of Technology Ladkrabang in 2009, and He received D.Eng from Kyushu University. He is currently Senior researcher at Agency for The Assessment and Application of Technology. His field of interests includes smart grid power system, Electric Vehicle and renewable energy.

Khamda Herbandono was born in Blora, Indonesia, on September 12, 1981. He has done his M.Eng. (M.T.) Degree in Metalurgy \& Material Engineering from University of Indonesia in 2011 and an B.Eng (S.T.) from Mechanical Engineering Department, National Institute of Technology in 2003. He is currently Senior Engineer at Agency for The Assessment and Application of Technology. His field of interests includes manufacturing and energy power system. 